\title{
Efficiency of scrum the most widely adopted method for agile software development
}

\author{
Md. Fazla Elahe ${ }^{1}$, S.M. Hasan Mahmud ${ }^{2}$ \\ ${ }^{1}$ (Lecturer, Department of Software Engineering, Daffodil international University, Bangladesh) \\ ${ }^{I}$ (Lecturer, Department of Software Engineering, Daffodil international University, Bangladesh)
}

\begin{abstract}
In the recent past there has been a revolution in software industries. This is because of the software industries have increasingly been adopting agile practices. Scrum is the most widely adopted agile method which is said quick and interactive way for developing software. This paper aims measuring efficiency of scrum as efficiency is one of the most important principle for getting economic advantage. To meet our set goal we will use data envelopment analysis (DEA) in concern with scrum.
\end{abstract}

Keywords: Agile, Data Envelopment Analysis (DEA), Efficiency, Key performance indicator (KPI), Scrum.

\section{Introduction}

Scrum, which is a process framework and is being using for complex software development since 1990[1]. One of the key principle of scrum is it gives opportunity to the customer to change their requirement when the developing process is going on. Scrum has all the properties according to the agile manifesto thus it is called one of the agile development process[2]. The word scrum comes from the game named rugby where a scrum refers to the manner of restarting the game after a minor infraction [3]. The aim of this paper is to find a way to measure the efficiency of scrum. Measuring efficiency of a software development process is not an easy task as it depends to a lot of key performance indicator (KPI). Innovation efficiency is related to the concept of productivity $[4,5]$. We will show how we can use data envelopment analysis (DEA), which is a non-parametric linear programming method to measure relative efficiency of scrum team. We will also discuss some key performance indicators so that we can measure efficiency more accurately.

\section{Related Works}

Agile methodologies are a set of practices for developing software and have been created by experienced people [6]. While agile is advocated by many experienced people at this time among all the agile methodologies, scrum is used by a big number of software industries. There must have some reasons behind it. Scrum paves the way to deliver software efficiently and interactively. If we say scrum is a framework to deliver software efficiently than one question arises, how do we can say that scrum is efficient? There must have some measurement technique to measure efficiency of scrum. Scrum is a continuous development process and the requirement may change at any time so that its quite a bit hard to measure the efficiency. We will use Data Envelopment Analysis (DEA) which is a tool for assessing the relative efficiency and is introduced by Charnes, Cooper and Rhodes (1978) [7]. Bruce Hollingsworth wrote a paper titled "Non-Parametric and Parametric Applications Measuring Efficiency in Health Care" there he uses DEA to measure the efficiency in health care [8]. Nicole Adler and Adiraveh shows the way to present DEA graphically[9]. Aneesh Chinubhai uses DEA for measuring efficiency in software development project [10]. Ž. Antolić shows some key performance indicator (KPI) for Software Development Process Efficiency Evaluation [5]. V. Mahnic, N. Zabkar uses burn down chart for Measuring Progress of Scrum-based Software Projects [11].

\section{A Big Picture Of Scrum}

Two facts are necessary to develop software using scrum. One is scrum team and another is scrum event. Scrum team consists of a product owner, development team and a scrum master. Product owner is the person who is responsible for maximizing the value of the product and for managing the product backlogs. Product backlog is the list of requirements that might have to done. Development team consists of professional who deliver releasable software according to the sprint backlog. Sprint is father of all scrum events and a time boxed within which increment is created. Scrum master is the leader of the scrum team. The main responsibility of scrum master is to maximize the value created by scrum team. 


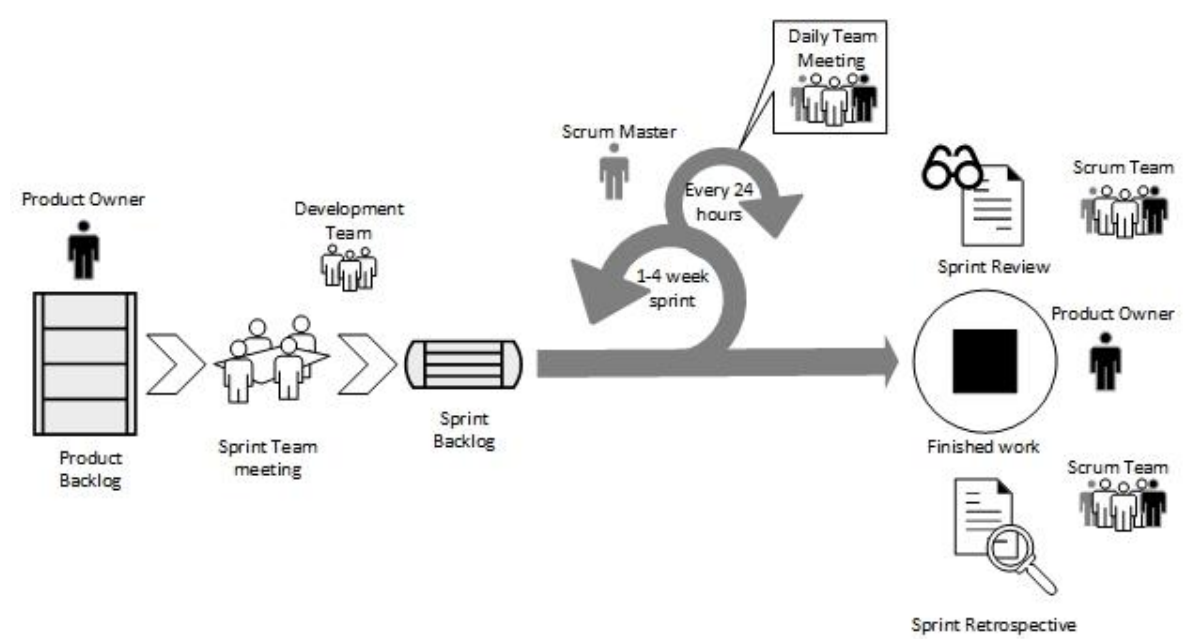

Figure 1 A big picture of Scrum

Scrum event is composed of four formal events. The events are sprint planning, daily scrum, sprint review and sprint retrospective. Sprint planning is time boxed eight hours maximum for one month of scrum within which scrum team decide the works to perform in this sprint. Daily scrum is time boxed maximum fifteen minutes within which they plan for next twenty-four hours. Sprint review is time boxed maximum four hours for one month sprint within which they review what has done in this sprint. Sprint Retrospective is a time boxed maximum three hours with in which scrum team identifies improvements of previous sprint and make a plan to implement it to next sprint.

\section{Productivity And Efficiency}

There is a distinct difference between productivity and efficiency. Productivity means the ratio of its input and output. Measuring productivity is easy when it uses single input and produce single output. But it becomes a bit complex when input or output is more than one. On the other hand efficiency is the comparison with the other system which produces same output with the need of less input or which use same input but produces more [12]. But the similarity between this two is they both are success indicator. Efficiency which sometimes called as production efficiency is composed of two components. One is called as technical efficiency used to measure a firm's success in producing maximum output or a set of output from a given set of inputs. Another is called as allocative efficiency which measure a firm's success in choosing an optimal set of input [13]. Data Envelopment Analysis or DEA is used to measure efficient production frontier. With DEA we can measure technical efficiency as well as allocative efficiency.

\section{Data Envelopment Analysis (DEA)}

Building on the ideas of Farrell (1957), DEA is proposed by Charnes, Cooper \& Rhodes (1978). It became a powerful analytical tool for measuring and evaluating performance of many types of entities thirty years back. We can use it to measure relative efficiency among the entities (called Decision making unit or DMU) which use common set of input to generate a common set of output [14].

Consider the following data of five scrum teams to measure relative efficiency. Team member and non salary costs are the input of each Decision making unit (DMU) and value produced by the teams are outputs.

\begin{tabular}{|l|l|l|l|l|l|}
\hline $\begin{array}{l}\text { Scrum } \\
\text { Team }\end{array}$ & $\begin{array}{l}\text { Team } \\
\text { member }\end{array}$ & $\begin{array}{l}\text { Non salary cost } \\
\text { (Thousand) }\end{array}$ & $\begin{array}{l}\text { Value produced } \\
\text { (Thousand) }\end{array}$ & $\begin{array}{l}\text { Team members per } \\
\text { value produced } \\
\text { (Thousand) }\end{array}$ & $\begin{array}{l}\text { Non salary costs } \\
\text { (Thousand) per value } \\
\text { produced (Thousand) }\end{array}$ \\
\hline ST1 & 20 & 6 & 20 & 1 & 0.3 \\
\hline ST2 & 60 & 12 & 30 & 2 & 0.4 \\
\hline ST3 & 20 & 2 & 10 & 2 & 0.2 \\
\hline ST4 & 60 & 3 & 20 & 3 & 0.15 \\
\hline ST5 & 50 & 2 & 10 & 5 & 0.2 \\
\hline
\end{tabular}

Table 1 Example data of Scrum teams

If we plot the above data in a graph then we can find those scrum teams closest to the axes are the most efficient. So a frontier can be drawn including ST1, ST3 and ST4 and extend it to both axes. 


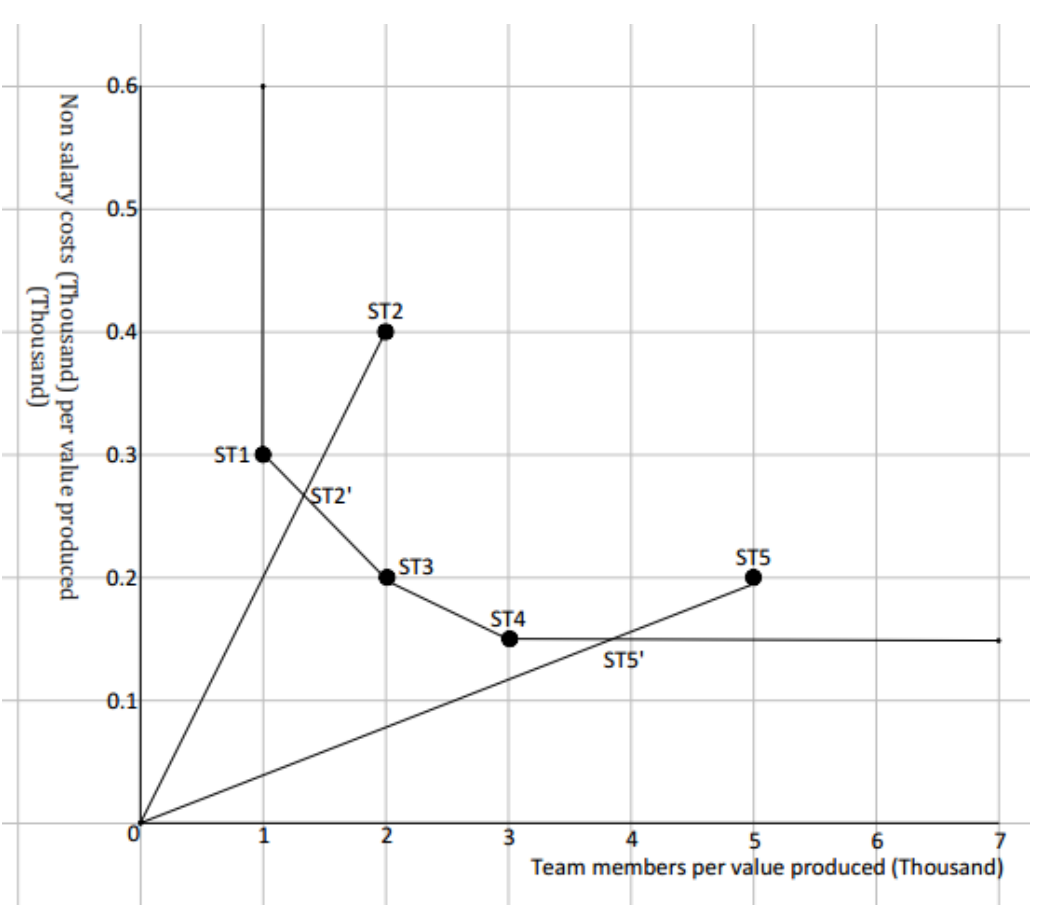

Figure 2 Relative efficiency of Scrum team

From the above figure we can decide that ST1, ST3 and ST5 are on efficient frontier so we can consider these three trams are on best practice. On the other hand ST2 and ST5 are less efficient in comparison with the others as they can reduce their input and maintain same level of output.

It is easy to implement this simple example of data in two-dimensional diagram. However, it is necessary to implement mathematical formula if the input and output is more.

\section{Key Performance Indicator}

Key performance indicator or KPI is a set of factors that are used to measure performance. Performance is the result of the simultaneous pursuit of efficiency, effectiveness where effectiveness implies a relationship between outputs and outcomes [15]. So far for our above example we have used two factors for input and one factor for output. There are some other KPI which can be used for measuring efficiency more accurately. Velocity is one of the KPI which determines the sum of story points completed per sprint per team. Story cycle time is considered to be one of the KPI which indicates Average number of days user stories were in a "committed to done" state on a sprint-by-sprint basis. We can also consider defects per release cycle as a KPI.

\section{Formulate DEA}

DEA is non-parametric linear programming based technique for evaluating the relative efficiency of decision making units(DMU's). If we denote $\mathrm{x}_{\mathrm{ij}}$ for observed magnitude of I type input for DMU $\mathrm{j}\left(\mathrm{x}_{\mathrm{ij}}>0\right.$; $\mathrm{i}=1,2, \ldots . \mathrm{m} ; \mathrm{j}=1,2, \ldots \ldots \mathrm{n})$ and $\mathrm{y}_{\mathrm{kj}}$ denote the observed of $\mathrm{k}$ type output for DMU $\mathrm{j}\left(\mathrm{y}_{\mathrm{kj}}>0 ; \mathrm{k}=1,2, \ldots . .1 ; \mathrm{j}=1,2, \ldots \ldots \mathrm{n}\right)$ then we can formulate relative efficiency

Where $\mathrm{v}_{\mathrm{i}}$ is the weights to be determined for input $\mathrm{i}$,

$$
\begin{gathered}
\text { Maximize } \theta_{\mathrm{j}}=\frac{\sum_{k=1}^{l} u_{k} y_{k j}}{\sum_{i=1}^{m} v_{i} x_{i j}} \\
\text { Subject to } \frac{\sum_{k=1}^{l} u_{k} y_{j}}{\sum_{i=1}^{m} v_{i} x_{j}} \leq 1
\end{gathered}
$$

$\mathrm{u}_{\mathrm{k}}$ is the weights to be determined for output $\mathrm{k}$,

And $\theta_{\mathrm{j}}$ is the relative efficiency of $\mathrm{DMU}_{\mathrm{j}}$ 
If the denominator becomes 0 then the above equation will be invalid. However if we fix the denominator to 1 then

$$
\begin{gathered}
\text { Max } \theta_{\mathrm{j}}=\sum_{k=1}^{l} u_{k} y_{k j} \\
\text { Subject to } \sum_{i=1}^{m} v_{i} x_{i j}=1 \\
\sum_{k=1}^{l} u_{k} y_{k j} \leq \sum_{i=1}^{m} v_{i} x_{i j} \\
\sum_{k=1}^{l} u_{k} y_{k j}-\sum_{i=1}^{m} v_{i} x_{i j} \leq 0
\end{gathered}
$$

The mathematical formula given above is a linear program and we can use any familiar program package to calculate efficiency of scrum team.

\section{Conclusion}

Although scrum is introduced in 1990 but the use of scrum has got acceleration in the recent past. [3]. Scrum enables us delivering products interactively over contract negotiation. That's why most companies are adopting scrum as their development practice. Efficiency is one of the most important principles of business and it has a close relation with economic benefit. Throughout this paper we have shown that how DEA can be used to measure relative efficiency of a scrum team. Thus we can measure efficiency of a scrum team and make our decision according to the result to use the scrum in more productive way.

\section{References}

[1] Ken Schwaber and Jeff Sutherland, The Scrum Guide ${ }^{\mathrm{TM}}$ (July 2013).

[2] Beck, K., Beedle, M., van Bennekum, A., Cockburn, A., Cunningham, W., Fowler, M., Grenning, J., Highsmith, J., Humt, A., Je® ries, R., Kern, J., Marick, B., Martin, R.C., Mellor, S., Schwaber, K., Sutherland, J., Thom, D., Manifesto for agile software development. Website (2001) http://agilemanifesto.org/.

[3] http://en.wikipedia.org/wiki/Scrum_(software_development)

[4] Hugo Hollanders and Funda Celikel Esser, Measuring innovation efficiency INNO-Metrics Thematic Paper (December 2007).

[5] Ž. Antolić, An Example of Using Key Performance Indicators for Software Development Process Efficiency Evaluation. R\&D Center Ericsson Nikola Tesla d.d.

[6] Kuda Nageswara Rao, G. Kavita Naidu, Praneeth Chakka, A Study of the Agile Software Development Methods, Applicability and Implications in Industry. International Journal of Software Engineering and Its Applications, Vol. 5 No. 2 , April- 2011.

[7] Milan M. Martic, Marina S. Novakovic, Alenka Baggia, Data Envelopmentent Analysis - Basic Models and their Utiliatilization. Organizacija, Volume 42, Number 2, March-April 2009 DOI: 10.2478/v10051-009-0001-6

[8] Bruce Hollingsworth, Non-Parametric and Parametric Applications Measuring Efficiency in Health Care, Health Care Management Science 6, 203-218, 2003 ,2013 Kluwer Academic Publishers.

[9] Nicole Adler*, Adi Raveh, Presenting DEA graphically, Omega 36 (2008), 715 - 729.

[10] Aneesh Chinubhai, Efficiency in Software Development Projects International Journal of Software Engineering and Its Applications, Vol. 5 No. 4, October, 2011.

[11] V. Mahnic, N. Zabkar, Measuring Progress of Scrum-based Software Projects Elektronika Ir Elektrotechnika, ISSN 1392-1215, VOL. 18, NO. 8, 2012.

[12] Harold O. Fried, C. A. Knox Lovell, Shelton S. Schmidt, The Measurement of Productive Efficiency : Techniques and Applications, ISBN:0-19-507218-9.

[13] G. Anandalingam, Nalin Kulatilaka, Decomposing production efficiency into Technica, Allocative and Structural Components, Journal of the Royal Statistical Society, Series A(General), Volume 150, Issue 2(1987), 143-151.

[14] http://en.wikipedia.org/wiki/Data_envelopment_analysis

[15] Diana Marieta Mihaiu, Alin Opreana, Marian Pompiliu Cristescu, efficiency, effectiveness and performance of the public sector. Romanian Journal of Economic Forecasting - 4/2010. 